\title{
Management and Diagnosis Challenges in Cystic Meningioma. A Case Report and Review of Literature
}

\author{
Mustapha Hemama 1,2, Nourou Dine Adeniran Bankole ${ }^{1,2 *}$, Moussa Denou ${ }^{1,2}$, Kaoutar Znati ${ }^{2,3}$, \\ Nizare El Fatemi1,2, Moulay Rachid El Maquili1,2 \\ ${ }^{1}$ Neurosurgery Department, Ibn Sina Hospital, Rabat, Morocco \\ ${ }^{2}$ Mohammed V University, Rabat, Morocco \\ ${ }^{3}$ Neuroanatomopathology Department, Ibn Sina Hospital, Rabat, Morocco \\ Email:mhemama@yahoo.com, ^bankolenouroudine@yahoo.fr, moussadenou@yahoo.fr, kaoutarznati@gmail.com, \\ nizareelfatemi@gmail.com,rachidelmaaquili@hotmail.com
}

How to cite this paper: Hemama, M., Bankole, N.D.A., Denou, M., Znati, K., El Fatemi, N. and El Maquili, M.R. (2020) Management and Diagnosis Challenges in Cystic Meningioma. A Case Report and Review of Literature. Open Journal of Modern Neurosurgery, 10, 222-229.

https://doi.org/10.4236/ojmn.2020.102023

Received: January 13, 2020

Accepted: February 25, 2020

Published: February 28, 2020

Copyright $\odot 2020$ by author(s) and Scientific Research Publishing Inc. This work is licensed under the Creative Commons Attribution International License (CC BY 4.0).

http://creativecommons.org/licenses/by/4.0/

\section{(c) (i) Open Access}

\begin{abstract}
Background: Cystic meningioma is a rare variety of meningioma. It represents $4 \%$ to $7 \%$ of all meningiomas. The authors report a case of intracranial cystic meningioma with a review of literature. Case Report: A 59-year-old female presented with a history of headache followed by left side hemiplegia. CT scan and MRI of the brain showed a right parietal tumor with double solid and cystic components thought to be pilocytic astrocytoma or metastasis preoperatively. At surgery, the extraaxial solid and cystic lesion had a well defined capsule that could be easily separated from the perilesional cortical surface. The tumor was totally removed and the cyst was punctioned. The histological study showed a cystic meningioma WHO Grade I. A follow-up at 10 months after surgery, the patient was going well and recovered from the hemiplegiaa. Conclusion: Cystic meningioma is an uncommon tumor that should be considered in the differential diagnosis of brain tumors with a cystic component. The preoperative diagnosis and management could be in some cases challenging.
\end{abstract}

\section{Keywords}

Meningiomas, Cyst, Differential Diagnosis, Case Report

\section{Background}

Meningiomas are the most common extra-axial tumours, accounting for 15\% of all intracranial tumours. Although imaging is typical for these lesions, there are 
many atypical forms, such as cystic meningioma, lipoblastic meningioma and meningioma in atypical positions [1] [2]. Cystic meningioma is a relatively rare condition that is more frequently found in males particularly in the frontoparietal areas men [3]. The clinical manifestations of cystic meningioma include, but are not limited to headaches, seizures, dizziness, personality changes and motor disturbance [4] [5] [6]. Preoperatively, the diagnosis of cystic meningioma may pose a dilemma especially in cases based exclusively on CT imaging. Although there are less dilemmas with MRI, cystic menangiomat can easily be misdiagnosed (in about $20 \%$ of cases) particularly as glial tumour, metastasis, neuroblastoma or haemangioblastoma [7]. Surgical removal of the entire tumor and its cyst remains the predominant treatment for cystic meningioma [5] [6]. We report here a rare case of intracranial cystic meningioma, and review the importance of preoperative diagnosis as well as the management and perprocedure challenges.

\section{Case Report}

A 59-year-old female presented to our Department with a 5-months history of headaches followed by left side hemiplegia over the previous 3 months preceding her admission. Other than hypertension, the patient did not present a significant medical or surgical history.

\section{Investigations}

First, a CT scan was performed. On unenhanced images, a large, complex, peripheral mass located in the right frontoparietal region was found (Figure 1). Hypodense cystic components were depicted in an otherwise isodense mass. After iodinated contrast injection, an intense enhancement of the solid component as well as a perilesional oedema was noted. Glioma, metastasis and meningioma were retained in the differential diagnosis. Brain MRI showed a right frontoparietal extraaxial tumor with double solid and cystic components thought to be pylocytic astrocytoma or metastasis preoperatively (Figure 2(a)

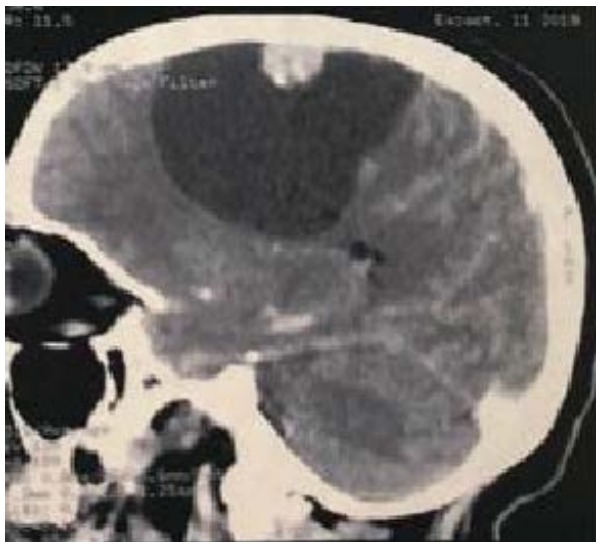

(a)

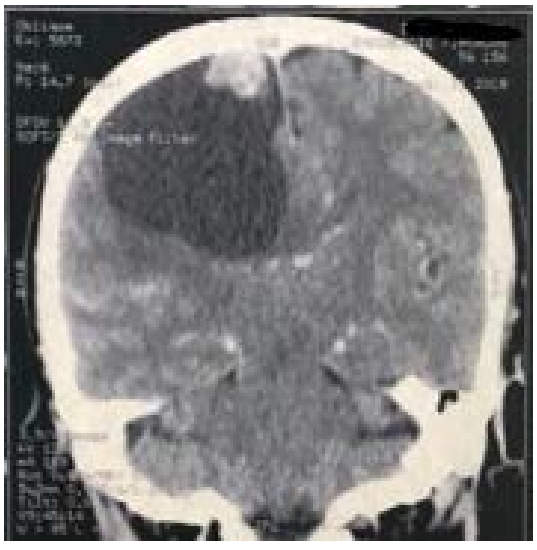

(b)

Figure 1. Sagittal and coronal view CT scan with contrast showing solid mass and peripheral large cyst. 


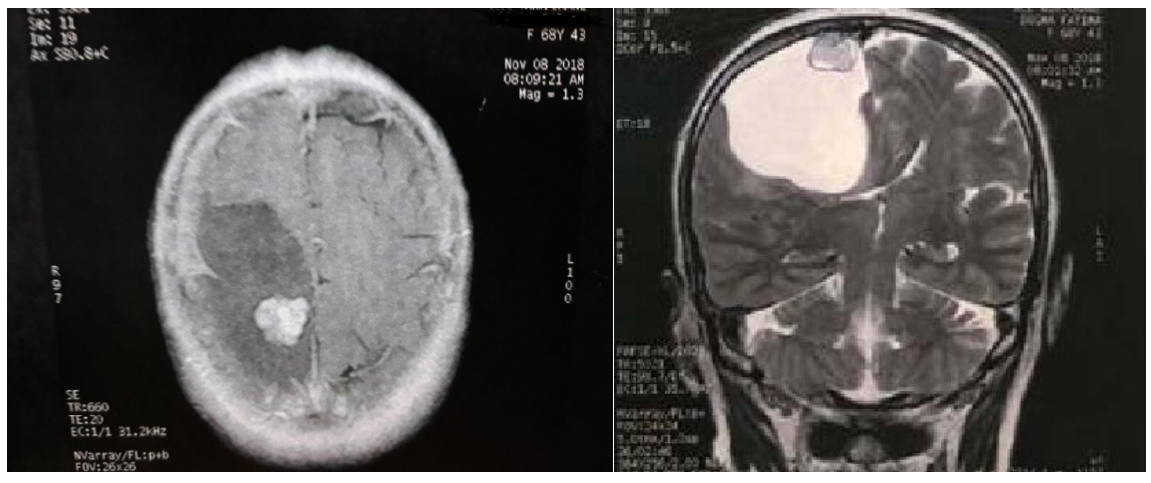

(a)

(b)

Figure 2. MRI axial and coronal view, showing fronto-parietal solid mass with peripheral large cyst extra-axial, according to the ELFiki Classification Type I.

and Figure 2(b)).

\section{Management}

The patient underwent general anaesthesia. A large right fronto-parietal craniotomy was performed and the dural plane was opened around the implantation of the lesion. The solid and cystic lesion had a well defined capsule that could be easily separated from the perilesional cortical surface. The tumor was totally reduced using an aspirator and then dissected near the cerebral parenchyma respecting its pial plane after the dirty yellow cyst was carefuly punctioned (Figure 3(a)). A complete excision of the lesion was carried out (Figure 3(b)) after whicha dural plasty was performed to cover the meningeal defect of the tumour implantation. The histolopathological study showed a cystic meningioma (Figure 5(a) and Figure 5(b)).

\section{Outcome and Follow-Up}

The postoperative outcome was favourable with less recovery of neurological deficit. The control CT scan excluded surgical complication such as haemorrhage and confirm our SIMPSON I resection (Figure 4). The patient was discharged 10 days after surgery without neurological impairment and physiotherapy was prescribed. Ten months after the surgery, the patient was going well and recovered from the hemiplegia.

\section{Discussion}

Cystic meningiomas are rare, accounting for 4\% - 7\% of all meningiomas [8] [9]. The most common site for the appearance of cystic meningiomas is the cerebral convexity, particularly the frontal and parietal lobes, while the cerebral falx is the second most frequent location [10]. In addition, cystic meningiomas can also be identified in the cerebellopontine angle, olfactory groove, suprasellar, falx and ventricle, trigeminal nerve or optic nerve [8] [11] [12] [13] [14].

The imaging features of an extra-axial meningioma are a broad dural base 


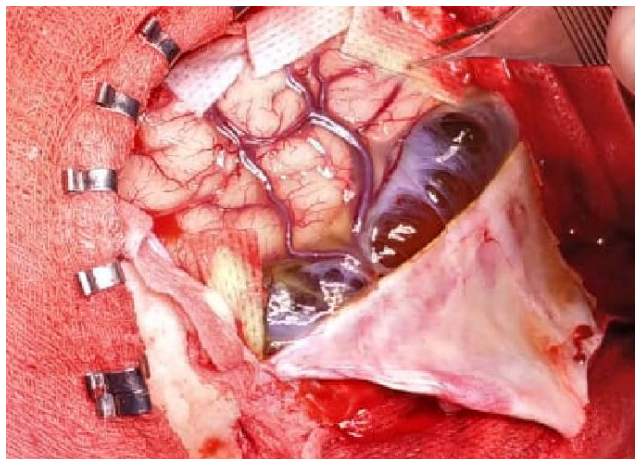

(a)

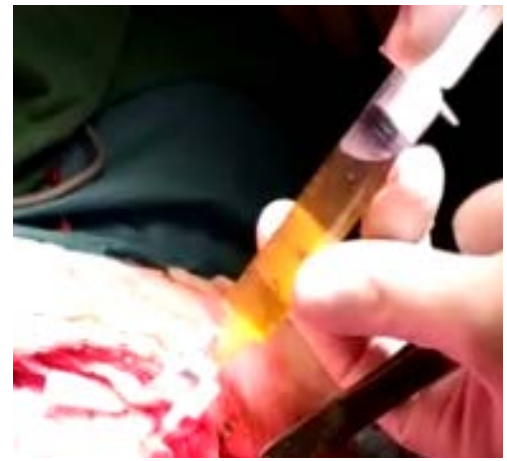

(b)

Figure 3. Perprocedure view showing the mass lesion and the dirty yellow cyst ponctioned according with the correlation between EL Fiki classification system with Nauta's (Type 1 corresponds to Type C).

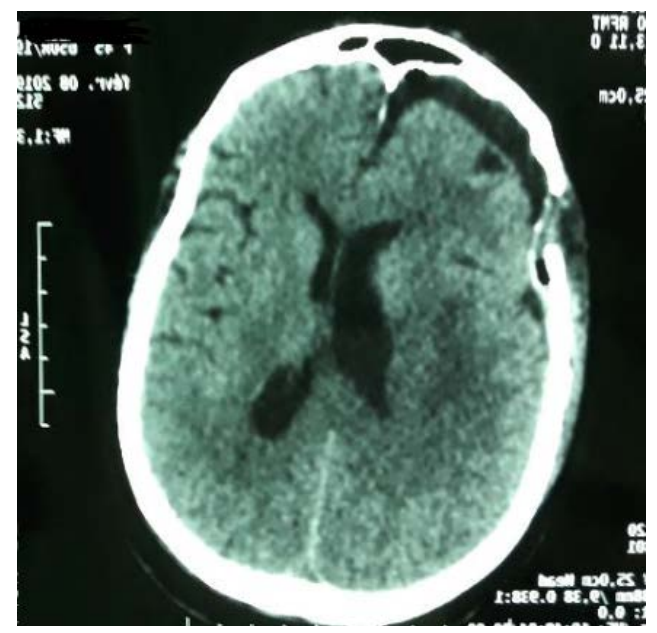

Figure 4. Post-procedure ct scan axial view showing total excision.

with a tail, the presence of cerebrospinal fluid (CSF) or vascular cleft between meningioma and normal parenchyma, white matter buckling and cortical thinning [15]. In a study by Goldsher et al. (1990), three criteria were proposed for the definition of the tail: presence on at least two consecutive images, greatest thickness next to the tumour with tapering away from it and enhancement greater than the tumour itself [16]. Although multiplanar reconstruction on CT or MRI may differentiate extra-axial from intra-axial tumours, a meningioma can mimic an intra-axial lesion when invaginating in the brain [17]. MRI remains the optimal diagnostic means for the diagnosis of cystic meningioma, but it is not sufficient to determine the particular tumor type. Only microsurgical inspection and histological examination can lead to the final diagnosis of the type of cystic meningioma [18]. However,combined MRI and diffusion-weighted imaging (DWI) may be efficient in diagnosing the type of cystic meningioma [15] [19]. Contrast-enhanced MRI may assist surgeons in determining whether neoplastic cells are present in the cystic wall; however, the 
wall could be enhanced despite the absence of tumor cells [20]. Nauta (1979) classified cystic meningiomas into four types (Table 1) [21]. In Type 1, the cystic component is entirely contained within the tumour and centrally located. In Type 2, the cyst is wholly intratumoural but peripherally located and encapsulated by tumour cells. In Type 3 , the cyst is peripherally located and lies in the adjacent parenchyma while in Type 4, the cyst is limited to the interface between the tumour and the brain as loculation of the CSF in the subarachnoid space, so it is not located in the tumour nor in the cerebral parenchyma [21]. Jung et al. [8] added Type $\mathrm{V}$ as a mixed type of meningioma combining Types I and III. In our case, the cystic meningioma was Type 1 (Figure 2(a) and Figure 2(b)).

In addition, El-Fiki et al. (1996) correlated the location of the cyst and its content and also described four types (Table 2). In type $A$, the cyst is extratumoural and contains clear water or CSF-like fluid. It can be subdivided into Type A1 when entrapped CSF is found and the cyst is surrounded by an arachnoid membrane, and into $\mathrm{A} 2$ when the content is the result of an excretory process of the tumour cell or an exudation without the presence of arachnoid separation. In type B, the content is a xanthochromic fluid and in B1 the cyst is extratumoural without a definite wall, while in B2 the fluid is surrounded by a

Table 1. Nauta's classification of cystic meningioma.

\begin{tabular}{cl}
\hline Type of Cystic Meningioma & \multicolumn{1}{c}{ MRI caracthéristics } \\
Type I & Cyst entirely contained within the tumour, centrally located \\
Type II & $\begin{array}{l}\text { Cyst entirely contained within the tumour, peripherally located } \\
\text { Type III }\end{array}$ \\
Cyst peripherally located relative to the tumour but lying in the \\
adjacent parenchyma \\
Cyst peripherally located but lying between the tumour and the \\
adjacent parenchyma
\end{tabular}

Table 2. El-Fiki's classification of cystic meningioma per-procedure.

\begin{tabular}{|c|c|c|}
\hline Type & Content & Location \\
\hline Type A & Clear water or CSF-like fluid & $\begin{array}{l}\text { A1 Extratumoural, CSF } \\
\text { surrounded by arachnoid } \\
\text { membrane } \\
\text { A2 Extratumoural, clear water } \\
\text { without the presence of } \\
\text { arachnoid membrane }\end{array}$ \\
\hline Type B & Xanthochromic fluid & $\begin{array}{l}\text { B1 Extratumoural, no wall } \\
\text { B2 Intratumoural, thin rim of } \\
\text { enhancing tumour } \\
\text { surrounding the cyst or } \\
\text { enhancing nodule }\end{array}$ \\
\hline Type C & Dark brown or yellow dirty fluid & Intratumoural \\
\hline Type D & Contains both clear-water & $\begin{array}{l}\text { Extratumoural or peritumoural cysts and } \\
\text { dark brown intratumoural small cysts }\end{array}$ \\
\hline
\end{tabular}

CSF, cerebrospinal fluid. 
thin rim of enhancing tumour or enhancing nodule. An intermediate degree of oedema accompanies the cyst. In type C, dark brown or yellow dirty intratumoural fluid was found accompanied by marked peritumoural oedema. Type D includes meningiomas with the presence of both clear extratumoural or peritumoural cysts and small dark brown intratumoural cyst [22]. The use of this classification showed in our case a Type C cystic meningioma (Figure 3(a)). Moreover, El-Fiki correlated his classification system with Nauta's and noted that Type 1 corresponds to Type C, Type 2 to Type B2, Type 3 to B1 or A2 and Type 4 to A1 (Table 3). In our case, this corelation was found perprocedural. The differential diagnosis of these lesions depends on the location. For supratentorial masses, high-grade gliomas and metastases have to be included. In infratentorial lesions, schwannomas with cystic degeneration, metastases and hemangioblastoma in adults and pilocytic astrocytomas in children have to be considered [1].

The diagnosis of meningioma have to be confirmed by histopathological examination in all of the cyst types. In our case, the histological analysis revealed a microcystic meningioma World Health Organization (WHO) grade I (Figure 5(a) and Figure 5(b)). Although there is no significant correlation between cyst formation and any particular histological type [23], Weber et al. (2003) found a correlation between peritumoural cystic meningiomas and atypical histological types [24].

\section{Conclusion}

Cystic meningiomas are rare forms of meningiomas that do not show

Table 3. Correlation of Nauta's and El-Fiki's classification.

\begin{tabular}{ccccc}
\hline Author & \multicolumn{5}{c}{ Classifications } \\
\hline $\begin{array}{c}\text { Nauta's } \\
\text { M EL-Fiki's }\end{array}$ & I & II & III & IV \\
Necessitating surgical excision of the cystic \\
$\begin{array}{c}\text { component } \\
\text { Com }\end{array}$ & Yes & Yes & No & A1 No \\
\hline
\end{tabular}

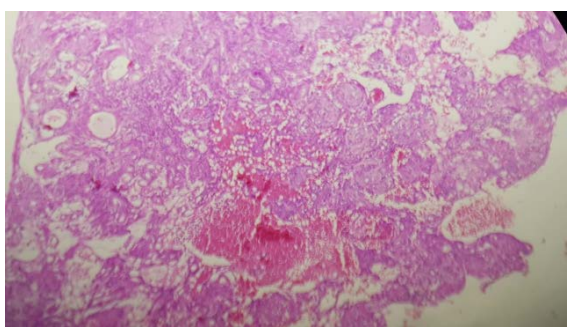

(a)

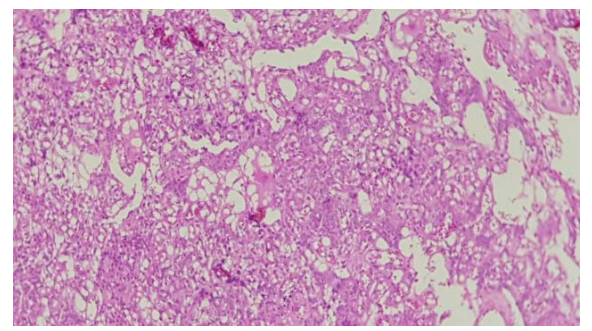

(b)

Figure 5. (a) and (b): Tumor proliferation of moderate and homogeneous cellularity composed of endothelial cells which are arranged in microcystic structures. Foci of classic menigothelial meningioma without cerebral parenchyma observed on the periphery. Histological appearance of a microcystic meningioma grade I WHO. 
pathognomonic radiological findings. The presence of cystic components within and/or around the mass usually suggests a diagnosis other than meningioma. These tumours can be easily misdiagnosed as metastases, gliomas and hemangioblastomas macroscopically in CT or MRI. Histopathological diagnosis is always required to confirm the diagnosis of meningioma. The outcome and follow up is generally favorable and good.

\section{Conflicts of Interest}

The authors have not any conflict interest in this case report and any financial resources.

\section{References}

[1] Sotiriadis, C., et al. (2015) Cystic Meningioma: Diagnostic Difficulties and Utility of MRI in Diagnosis and Management. BMJ Case Reports, 2015, pii: bcr2014208274. https://doi.org/10.1136/bcr-2014-208274

[2] Buetow, M.P., Buetow, P.C. and Smirniotopoulos, J.G. (1991) Typical, Atypical, and Misleading Features in Meningioma. Radiographics, 11, 1087-1106. https://doi.org/10.1148/radiographics.11.6.1749851

[3] Worthington, C., Caron, J.L., Melanson, D., et al. (1985) Meningioma Cysts. Neurology, 35, 1720-1724. https://doi.org/10.1212/WNL.35.12.1720

[4] Wang, P.F., Han, S., Liu, N., et al. (2016) Peritumoral Cystic Meningioma: A Report of Two Cases and Review of the Literature. Experimental and Therapeutic Medicine, 11, 904-908. https://doi.org/10.3892/etm.2016.2999

[5] Zee, C.S., Chen, T., Hinton, D.R., et al. (1995) Magnetic Resonance Imaging of Cystic Meningiomas and Its Surgical Implications. Neurosurgery, 36, 482-488. https://doi.org/10.1097/00006123-199503000-00006

[6] Rishi, A., Black, K.S., Woldenberg, R.W., et al. (2011) Microcystic Meningioma Presenting as a Cystic Lesion with an Enhancing Mural Nodule in Elderly Women: Report of Three Cases. Brain Tumor Pathology, 28, 335-339. https://doi.org/10.1007/s10014-011-0052-2

[7] Guan, T.K., Pancharatnam, D., Chandran, H., et al. (2013) Infratentorial Benign Cysticmeningioma Mimicking a Hemangioblastoma Radiologically and a Pilocytic Astrocytoma Intraoperatively: A Case Report. Journal of Medical Case Reports, 7, 87. https://doi.org/10.1186/1752-1947-7-87

[8] Jung, T.Y., Jung, S., Shin, S.R., et al. (2005) Clinical and Histopathological Analysis of Cystic Meningiomas. Journal of Clinical Neuroscience, 12, 651-655. https://doi.org/10.1016/j.jocn.2004.09.020

[9] Parisi, G., Tropea, R., Giuffrida, S., et al. (1986) Cystic Meningiomas. Report of Seven Cases. Journal of Neurosurgery, 64, 35-38.

https://doi.org/10.3171/jns.1986.64.1.0035

[10] Fortuna, A., Ferrante, L., Acqui, M., Guglielmi, G. and Mastronardi, L. (1988) Cystic Meningiomas. Acta Neurochirurgica, 90, 23-30. https://doi.org/10.1007/BF01541262

[11] Sridhar, K., Ravi, R., Ramamurthi, B. and Vasudevan, M.C. (1995) Cystic Meningiomas. Surgical Neurology, 43, 235-239. https://doi.org/10.1016/0090-3019(95)80004-Z

[12] Goyal, A., Singh, A.K., Gupta, V., Singh, D., Tatke, M. and Kumar, S. (2002) 
Suprasellar Cystic Meningioma: Unusual Presentation and Review of the Literature. Journal of Clinical Neuroscience, 9, 702-704. https://doi.org/10.1054/jocn.2002.1115

[13] Deb, P., Sahani, H., Bhatoe, et al. (2010) Intraventricular Cystic Meningioma. Journal of Cancer Research and Therapeutics, 6, 218-220. https://doi.org/10.4103/0973-1482.65247

[14] Zhi, L., Bing, L., Yang, L., et al. (2009) Cystic Papillary Meningioma with Subarachnoid Dissemination: A Case Report and Review of the Literature. Pathology Research and Practice, 205, 582-587. https://doi.org/10.1016/j.prp.2009.01.016

[15] Chen, T.Y., Lai, P.H., Ho, J.T., et al. (2004) Magnetic Resonance Imaging and Diffusion-Weighted Images of Cystic Meningioma: Correlating with Histopathology. Clinical Imaging, 28, 10-19. https://doi.org/10.1016/S0899-7071(03)00032-9

[16] Goldsher, D., Litt, A.W., Pinto, R.S., et al. (1990) Dural “Tail” Associated with Meningiomas on Gd-DTPA-Enhanced MR Images: Characteristics, Differential Diagnostic Value, and Possible Implications for Treatment. Radiology, 176, 447-450. https://doi.org/10.1148/radiology.176.2.2367659

[17] Bird, C.R., Hasso, A.N. and LeBeau, D.J. (1989) Meningiomas and Skull Base Neoplasms. Topics in Magnetic Resonance Imaging, 1, 52-68. https://doi.org/10.1097/00002142-198903000-00007

[18] Ferrante, L., Acqui, M., Lunardi, P., et al. (1997) MRI in the Diagnosis of Cystic Meningiomas: Surgical Implications. Acta Neurochirurgica, 139, 8-11. https://doi.org/10.1007/BF01850861

[19] Zhang, D., Hu, L.B., Zhen, J.W., et al. (2009) MRI Findings of Intracranial Cystic Meningiomas. Clinical Radiology, 64, 792-800. https://doi.org/10.1016/j.crad.2009.04.012

[20] Arai, M., Kashihara, K. and Kaizaki, Y. (2006) Enhancing Gliotic Cyst Wall with Microvascular Proliferation Adjacent to a Meningioma. Journal of Clinical Neuroscience, 13, 136-139. https://doi.org/10.1016/j.jocn.2005.02.015

[21] Nauta, H.J., Tucker, W.S., Horsey, W.J., et al. (1979) Xanthochromic Cysts Associated with Meningioma. Journal of Neurology, Neurosurgery, and Psychiatry, 42, 529-535. https://doi.org/10.1136/jnnp.42.6.529

[22] El-Fiki, M., el-Henawy, Y. and Abdel-Rahman, N. (1996) Cystic Meningioma. Acta Neurochirurgica, 138, 811. https://doi.org/10.1007/BF01411258

[23] Maiuri, F., Benvenuti, D., De Simone, M.R., et al. (1986) Cystic Lesions Associated with Meningiomas. Surgical Neurology, 26, 591-597. https://doi.org/10.1016/0090-3019(86)90347-2

[24] Weber, J., Gassel, A.M., Hoch, A., et al. (2003) Intraoperative Management of Cystic Meningiomas. Neurosurgical Review, 26, 62-66. https://doi.org/10.1007/s10143-002-0228-7 